\title{
Antimalarial activity of kinase inhibitor, nilotinib, in vitro and in vivo
}

\author{
Aki Ishiyama $^{1,2}$, Masato Iwatsuki ${ }^{1,2}$, Rei Hokari ${ }^{1}$, Masaaki Sawa ${ }^{3}$, Satoshi Ōmura ${ }^{2}$ and Kazuhiko Otoguro ${ }^{1}$
}

The Journal of Antibiotics (2015) 68, 469-472; doi:10.1038/ja.2015.7; published online 18 February 2015

Malaria has been historically recognized as one of the world's most devastating diseases. The World Health Organization now recommends Artemisinin-based Combination Therapies (ACTs) for treatment of malaria. However, it has been reported that the parasite sensitivity against ACTs is reduced significantly by the spread of parasites that have developed resistance to other antimalarial drugs, such as mefloquine and lumefantrine. ${ }^{1}$ Furthermore, it was reported that a molecular marker of artemisinin-resistant Plasmodium falciparum, PF3D7_1343700 kelch propeller domain (K-13-propeller), is associated with artemisinin resistance in parasites isolated in western Cambodia, where resistance to virtually all the known antimalarial drugs has been reported. ${ }^{2}$ Although parasite resistance to artemisinin has been detected only in South-East Asian countries, development of new antimalarial drugs, especially those having novel modes of action, is urgently required.

During antimalarial drug development around the world, it has been reported that several kinase inhibitors (staurosporine, cyclindependent kinase inhibitors, etc.) show moderate (or weak) in vitro antimalarial effects against erythrocytic stage parasites, and targets predicted to be related to kinases involved in the Plasmodium erythrocyte stage cycle, although the actual targets remain unknown. $^{3-7}$ In addition, P. falciparum kinases PfPK5, Pfmrk and PfPKA-C, regulating nuclear division in the erythrocytic stage parasite, were identified as potential drug targets and inhibitors are under development for innovating new antimalarial drugs. ${ }^{8-12}$ It was reported that there are 65 malaria eukaryotic protein kinases (ePKs) but no malaria kinases are classified into the tyrosine kinase (TK) group and sterile phenotype kinase group based on the analysis using several bioinformatics tools. ${ }^{13}$ Furthermore, it has been suggested that the Plasmodium parasite kinome is the most druggable, targeting not only erythrocytic stage parasite (asexual and sexual) but also the insect-dwelling and liver stages of the parasite. ${ }^{14,15} \mathrm{~A}$ recent paper also indicated that $36 \mathrm{ePKs}$ in the Plasmodium parasite kinome were essential for homeostasis in the P. falciparum erythrocytic asexual stage and also in the rodent malaria parasite ( $P$. berghei) orthologous from the phospho-proteomic analysis. ${ }^{16}$ However, there are no antimalarial drugs targeting Plasmodium kinases so far. In this paper, we report an evaluation of the antimalarial activity of clinically-used seven kinase inhibitor drugs against erythrocytic asexual stage parasites, as well as cytotoxicity against MRC-5 cells, to help determine their potential for antimalarial drugs. We found that nilotinib, approved for the treatment of chronic myeloid leukemia targeting Bcr-Abl TK, demonstrates in vitro antimalarial activity against erythrocytic asexual parasite stages. In vivo efficacy of nilotinib was also observed using a rodent malaria model.

The evaluation of antimalarial activity and cytotoxicity were conducted as previously reported. ${ }^{17}$ Briefly, cultured $P$. falciparum (chloroquine sensitive FCR3 strain and chloroquine resistant K1 strain) in Type A+ blood were seeded in 96-well culture plates (parasitaemia $0.5-1 \%$, Hematocrit 2.0\%) and incubated with test drugs for $72 \mathrm{~h}$. After incubation, parasite lactate dehydrogenase activity was assayed to determine parasite growth and calculate the antimalarial activity in comparison with the controls that had received no drugs. Cytotoxicity was tested against MRC- 5 cells. Cultured MRC- 5 cells were seeded in 96-well culture plates with $1 \times 10^{3}$ cells per well and test drugs were added to the each well on the following day. After 7 days of incubation, cell proliferation was determined by MTT assay allowing a calculation of cytotoxicity. Selectivity indexes (SIs) were calculated by the following formula: $\mathrm{SI}=\mathrm{IC}_{50}$ for cytotoxicity/ $\mathrm{IC}_{50}$ for antimalarial activity. In the in vivo evaluation, $P$. berghei $\mathrm{N}$ strain was administered into ICR (CD1) mice (dose of $2 \times 10^{6}$ parasites). First treatment was started $2 \mathrm{~h}$ post-infection (D0) and drug was administered every $24 \mathrm{~h}$ for 3 days (D1-3). Parasitaemia was determined on day 4 (D4) with blood smears to calculate the percentage inhibition.

All kinase inhibitors were obtained commercially in the form of clinically-used salts (Figure 1). Table 1 shows in vitro antimalarial activity, cytotoxicity against MRC-5 cells and SI of commercially available kinase inhibitor drugs (sunitinib, sorafenib, erlotinib, lapatinib, dasatinib, imatinib and nilotinib), ${ }^{18}$ along with two known antimalarial drugs chloroquine and artesunate. Among them, sunitinib, a multi-TK inhibitor, showed the most potent antimalarial activity $\left(\mathrm{IC}_{50}\right.$ : $0.11-0.15 \mu \mathrm{g} \mathrm{ml}^{-1}$ ), but it also displayed moderate cytotoxicity against MRC-5 cells $\left(\mathrm{IC}_{50}: 3.19 \mu \mathrm{g} \mathrm{ml}^{-1}\right.$ ). Sorafenib also known to inhibit several TKs in addition to its primary target B-Raf

${ }^{1}$ Research Center for Tropical Diseases, Kitasato Institute for Life Sciences, Kitasato University, Tokyo, Japan; ${ }^{2}$ Graduate School of Infection Control Sciences, Kitasato Institute for Life Sciences, Kitasato University, Tokyo, Japan and ${ }^{3}$ Drug Discovery Research, Carna Biosciences, Inc., Kobe, Japan

Correspondence: Dr M Iwatsuki or Professor S Ōmura, Kitasato Institute for Life Sciences, Kitasato University, 5-9-1 Shirokane, Minato-ku, Tokyo 108-8641, Japan.

E-mail: iwatuki@lisci.kitasato-u.ac.jp or omuras@insti.kitasato-u.ac.jp

Received 20 August 2014; revised 14 January 2015; accepted 16 January 2015; published online 18 February 2015 
<smiles>CCN(CC)CCNC(=O)c1c(C)[nH]c(/C=C2\C(=O)Nc3ccc(F)cc32)c1C</smiles><smiles>CNC(=O)c1cc(Oc2ccc(NC(=O)Nc3ccc(Cl)c(C(F)(F)F)c3)cc2)ccn1</smiles><smiles>C#Cc1cccc(Nc2ncnc3cc(OCCOC)c(OCCOC)cc23)c1</smiles><smiles>CC(O)(CCNCc1ccc(-c2ccc3ncnc(Nc4ccc(OCc5cccc(F)c5)c(Cl)c4)c3c2)o1)OS(C)(C)O</smiles><smiles>Cc1nc(Nc2ncc(C(=O)Nc3c(C)cccc3Cl)s2)cc(N2CCN(CCO)CC2)n1</smiles><smiles>Cc1cn(-c2cc(NC(=O)c3ccc(C)c(Nc4nccc(-c5cccnc5)n4)c3)cc(C(F)(F)F)c2)cn1</smiles>

Figure 1 Structures of kinase inhibitors. ${ }^{27-31}$

Table 1 In vitro antimalarial activity, cytotoxicity and Sls of kinase inhibitors

\begin{tabular}{|c|c|c|c|c|c|c|c|}
\hline \multirow[b]{4}{*}{ Compound } & \multirow[b]{4}{*}{ Target kinase } & \multicolumn{4}{|c|}{$I_{50}$} & \multirow{3}{*}{\multicolumn{2}{|c|}{$s p$}} \\
\hline & & \multicolumn{3}{|c|}{ Antimalarial activity } & \multirow[t]{2}{*}{ Cytotoxicity $^{a}$} & & \\
\hline & & \multicolumn{2}{|l|}{ PfK1 } & \multirow{2}{*}{$\begin{array}{c}\text { PfFCR3 } \\
\mu g \mathrm{ml}^{-1}(\mu / \mathrm{M})\end{array}$} & & & \\
\hline & & $\mu g m l^{-1}(\mu / M)$ & $S D$ & & $\begin{array}{c}M R C-5 \text { cells } \\
\mu g m l^{-1}(\mu / M)\end{array}$ & MRC-5/pfK1 & $M R C-5 / p f F C R 3$ \\
\hline Sunitinib & Multi & $0.15(0.28)$ & $\pm 0.01^{\mathrm{c}}$ & $0.11(0.21)$ & $3.19(5.99)$ & 21.3 & 29 \\
\hline Sorafenib & B-Raf+Multi & 8.66 (13.59) & ND & ND & $>100.00(>156.98)$ & $>11.5$ & - \\
\hline Erlotinib & TK (EGFR) & $>12.50(>29.08)$ & ND & ND & ND & - & - \\
\hline Lapatinib & TK (EGFR/HER2) & $1.66(1.76)$ & ND & ND & $4.4(4.66)$ & 2.7 & - \\
\hline Dasatinib & Bcr-Abl+Src family TK & $8.57(16.94)$ & ND & ND & 13.65 (26.98) & 1.6 & - \\
\hline Imatinib & Bcr-Abl TK & $8.02(13.6)$ & ND & ND & $14.5(24.59)$ & 1.8 & - \\
\hline Nilotinib & Bcr-Abl TK & $1.22(2.09)$ & $\pm 0.02^{c}$ & $0.64(1.01)$ & $89.07(152.52)$ & 73 & 139.2 \\
\hline Chloroquine $^{d}$ & & 301.09 (584.43) & \pm 4.67 & $19.78(38.41)$ & $18570(36045)$ & 61.7 & 938.8 \\
\hline Artesunate $^{d}$ & & $2.85(7.41)$ & \pm 0.1 & $1.84(4.78)$ & 15040 (39 123) & 5200 & 12800 \\
\hline
\end{tabular}

Abbreviations: ND, not determined; PfFCR3, chloroquine sensitive $P$. falciparum FCR3 strain; PfK1, chloroquine resistant $P$. falciparum K1 strain;

$\mathrm{SD}$, standard deviation; SI, selectivity index.
${ }^{a}$ Compounds with antimalarial (K1) IC 50 value of $<12.5 \mu \mathrm{g} \mathrm{ml}^{-1}$ were subjected to cytotoxicity evaluation $(n=1)$ using an MRC-5 cell line (normal human fetal lung fibroblast cells).

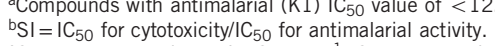

${ }^{c}$ Compounds showing $<1.56 \mu \mathrm{g} \mathrm{ml}-1$ I I 50 value against PfK 1 in the first screening $(n=1)$ were repeatedly experimented $(n=3)$ and also subjected to the anti-PfFCR3 activity assay ( $\left.n=1\right)$ to see whether they exhibited the results depending on the strain.

${ }^{\mathrm{d}} \mathrm{C}_{50}$ values were shown by $\mathrm{ng} \mathrm{ml}^{-1}$ and $\mathrm{nM}$.

kinase, a serine-threonine kinase, was moderately active against malaria parasites, with an $\mathrm{IC}_{50}$ value of $8.66 \mu \mathrm{g} \mathrm{ml}^{-1}$. Erlotinib and lapatinib are TK inhibitors specific to epidermal growth factor receptor (EGFR) or dual EGFR/HER2 receptors, respectively. Interestingly, erlotinib did not show any antimalarial activity below a concentration of $12.5 \mu \mathrm{g} \mathrm{ml}^{-1}$, but lapatinib exhibited a moderate antimalarial activity, with an $\mathrm{IC}_{50}$ value of $1.66 \mu \mathrm{g} \mathrm{ml}^{-1}$. Lapatinib is known to inhibit EGFR/HER2 receptors with very slow off-rate by inducing conformational change of kinases, ${ }^{19}$ suggesting that some kinases in the Plasmodium parasite kinome may exist that are sensitive to such compounds. The cytotoxicity $\left(\mathrm{IC}_{50}\right)$ of lapatinib was $4.4 \mu \mathrm{g} \mathrm{ml}^{-1}$ with a low SI of 2.7. Dasatinib, imatinib and nilotinib 
Table 2 In vivo antimalarial activity of nilotinib

\begin{tabular}{lccccc}
\hline & \multicolumn{3}{c}{ Dosage } & & \\
\cline { 2 - 3 } Compound & $m g \mathrm{~kg}^{-1}$ day $^{-1}$ & Duration & & Route & Inhibition (\%) \\
\hline Nilotinib & 30 & 4 days & i.p. & 36.3 \\
& 60 & & & 83.3 \\
& 30 & 4 days & p.o. & 23.9 \\
Artesunate & 60 & & & 75.8 \\
\hline
\end{tabular}

are all TK inhibitors targeting the Bcr-Abl kinase. Imatinib showed moderate antimalarial activity $\left(\mathrm{IC}_{50}\right.$ value of $8.02 \mu \mathrm{g} \mathrm{ml}^{-1}$ ) but its SI was 1.8 , because of the relatively low $\mathrm{IC}_{50}$ value against MRC-5 $\left(14.50 \mu \mathrm{g} \mathrm{ml}^{-1}\right)$. Dasatinib also inhibits other TKs belonging to the Src family, in addition to Bcr-Abl kinase, but it exhibits a similar potency and SI to imanitib, indicating that no kinases exist in the Plasmodium parasite kinome that are structurally similar to the Src family kinases. Niloitnib was a potent inhibitor against both the drug resistant strain (K1) and drug sensitive strain (FCR3), with $\mathrm{IC}_{50}$ values of 1.22 and $0.64 \mu \mathrm{g} \mathrm{ml}^{-1}$, respectively, coupled with a significantly safe profile (SI: 73.0 and 139.2, respectively). These results imply the possible existence of malaria kinases having a binding site structurally similar to that of human Abl kinase. To evaluate the antimalarial activity of nilotinib, we investigated in vivo antimalarial activity using a mouse model. As shown in Table 2, nilotinib displayed drug potency with $36.3 \%$ and $83.3 \%$ parasite growth inhibition in in vivo antimalarial evaluation when the mice were treated with nilotinib intraperitoneally (30 and $60 \mathrm{mg} \mathrm{kg}^{-1} \times 4$ i.p.). It was noteworthy that oral treatment with nilotinib also dose-dependently inhibited the parasite growth $(23.9 \%$ and $75.8 \%$ inhibition at 30 and $60 \mathrm{mg} \mathrm{kg}^{-1} \times 4$, p.o. respectively). The efficacy of nilotinib at $60 \mathrm{mg} \mathrm{kg}^{-1} \times 4$ oral treatment was comparable to that of artesunate, one of the most important clinically-used antimalarial drugs, with $10 \mathrm{mg} \mathrm{kg}^{-1} \times 4$ i.p. treatment.

As there are no TKs in the Plasmodium kinome, ${ }^{13}$ the observed antimalarial activity of nilotinib should not be via TK inhibition. The fact that other Abl kinase inhibitors, dasatinib and imatinib, also showed antimalarial activity, suggests a possibility of the existence of malaria kinases which has a pocket that is structurally similar to the ATP-binding site of human Abl kinase, although the antimalarial target of nilotinib is unknown. The core scaffold of nilotinib, a phenylaminopyrimidine, is a common substructure seen in ATPcompetitive kinase inhibitors. Imatinib, having the same core scaffold as nilotinib, showed in vitro antimalarial activity. There are also a few reports concerning ATP-competitive inhibitors of $P$. falciparum kinases, including PfPK5, PFPK7 and $p f C D P K 4 .^{20-22}$ Therefore, the molecular target of nilotinib might be one of the plasmodial kinases having an ATP-binding site similar to that of human Abl kinase.

Another plausible target is the oxidoreductase family. Rix et al. ${ }^{23}$ reported chemical proteomic analysis of Bcr-Abl inhibitors, imatinib, nilotinib and dasatinib, using K562 cells, and that imatinib and nilotinib were bound to the non-kinase target, oxidoreductase NQO2 (also known as QR2). This oxidoreductase was also identified as a novel target of the quinoline antimalarial chloroquine by Graves et al. $^{24}$

Although in vitro antimalarial activity of nilotinib was 271-581 times weaker than that of artesunate, in vivo antimalarial activity of nilotinib with $60 \mathrm{mg} \mathrm{kg}^{-1} \times 4$ was as effective as artesunate (using $\left.10 \mathrm{mg} \mathrm{kg}^{-1} \times 4\right)$. This result could imply that nilotinib has a better bioavailability, moreover it has about 24-48 times longer serum half-life, compared with artesunate or its active metabolite, dihydroartemisinin, in humans when administered orally. ${ }^{25,26}$

In conclusion, this paper identifies the in vitro and in vivo antimalarial activity of nilotinib, and these findings suggested that further investigation is needed to evaluate the possibility of using nilotinib for developing new antimalarials. Investigation of its mode of action is also currently under way.

\section{CONFLICT OF INTEREST}

The authors declare no conflict of interest.

\section{ACKNOWLEDGEMENTS}

This study was supported by the Japan Science and Technology (JST), Adaptable and Seamless Technology Transfer Program through Target-driven R\&D (A-STEP), Feasibility Study (FS) Stage, Seeds Validation (AS2321021G, 2010). We are grateful to Prof. Hirofumi Nakano and Prof. Andy Crump, Kitasato Institute for Life Sciences, Kitasato University, for valuable advice, suggestions and proofreading.

1 Taylor S. M. \& Juliana J. J. Artemisinin combination therapies and malaria parasite drug resistance: the game is afoot. J. Infect. Dis. 210, 335-337 (2014).

2 Ariey, F. et al. A molecular marker of artemisinin-resistant Plasmodium falciparum malaria. Nature 505, 50-55 (2014).

3 Ward, G. E. et al. Staurosporine inhibits inversion of erythrocyte by malarial merozoites. Exp. Parasitol. 79, 480-487 (1994).

4 Dluzewski, A. R. \& Garcia, C. R. Inhibition of invasion and intraerythrocytic development of Plasmodium falciparum by kinase inhibitors. Experientia 15, 621-623 (1996).

5 Gray, N. et al. ATP-site directed inhibitors of cyclin-dependent kinases. Curr. Med. Chem. 6, 859-875 (1999).

6 Gazarini M. L. \& Garcia C. R. Interruption of the blood-stage cycle of the malaria parasite, Plasmodium chabaudi, by protein tyrosine kinase inhibitors. Braz. J. Med. Biol. Res. 36, 1465-1469 (2003).

7 Zhao, Y. et al. Molecular cloning, stage-specific expression and cellular distribution of a putative protein kinase from Plasmodium falciparum. Eur. J. Biochem. 207, 305-313 (1992)

8 Ross-Macdonald, P. B. et al. Isolation and expression of a gene specifying a cdc2-like protein kinase from the human malaria parasite Plasmodium falciparum. Eur. J. Biochem. 220, 693-701 (1994).

9 Li, J. L. et al. Pfmrk, a M015-related protein kinase from Plasmodium falciparum. Gene cloning, sequence, stage-specific expression and chromosome localization. Eur. J. Biochem. 241, 805-813 (1996).

10 Syin, C. et al. The H89 cAMP-dependent protein kinase inhibitor blocks Plasmodium falciparum development in infected erythrocytes. Eur. J. Biochem. 268, 4842-4849 (2001).

11 Graeser, R. et al. Plasmodium falciparum protein kinase 5 and the malarial nuclear division cycles. Mol. Biochem. Parasitol. 82, 37-49 (1996).

12 Xiao, Z. et al. Design and synthesis of Pfmrk inhibitors as potential antimalarial agents. Bioorg. Med. Chem. Lett. 11, 2875-2878 (2001).

13 Ward, P. et al. Protein kinases of the human malaria parasite Plasmodium falciparum: the kinome of a divergent eukaryote. BMC Genomics 5, 79 (2004).

14 Doerig, C. et al. Protein kinases of malaria parasites: an update. Trends Parasitol. 24, 570-577 (2008).

15 Doerig C. et al. Malaria: targeting parasite and host cell kinomes. Biochim. Biophys. Acta. 1804, 604-612 (2010)

16 Solyakov, L. et al. Global kinomic and phospho-proteomic analyses of the human malaria parasite Plasmodium falciparum. Nat. Commun. 2, 565-577 (2011).

17 Otoguro, K. et al. Potent antimalarial activities of polyether antibiotic, X-206. J. Antibiot. 54, 658-663 (2001).

18 Knight, Z. A. et al. Targeting the cancer kinome through polypharmacology. Nat. Rev. Cancer. 10, 130-137 (2010).

19 Wood, E. R. et al. A unique structure for epidermal growth factor receptor bound to GW572016 (lapatinib): relationships among protein conformation, inhibitor off-rate, and receptor activity in tumor cells. Cancer Res. 64, 6652-6659 (2004).

20 Holton, S. et al. Structures of $P$. falciparum PfPK5 test the CDK regulation paradigm and suggest mechanisms of small molecule inhibition. Structure 11, 1329-1337 (2003).

21 Merckx, A. et al. Structure of $P$. falciparum protein kinase 7 identify an activation motif and leads for inhibitor design. Structure 16, 228-238 (2008).

22 Vidadala, R. S. et al. Development of potent and selective Plasmodium falciparum calcium-dependent protein kinase 4 (PfCDPK4) inhibitors that block the transmission of malaria to mosquitoes. Eur. J. Med. Chem. 74, 562-573 (2014). 
23 Rix, U. et al. Chemical proteomic profiles of the BCR-ABL Inhibitors, imatinib, nilotinib and dasatinib reveal novel kinase and non kinase targets. Blood 110, 4055-4063 (2007).

24 Graves, P. R. et al. Discovery of novel targets of quinoline drugs in the humanpurine binding proteome. Mol. Pharmacol. 62, 1364-1372 (2002)

25 Morris, C. A. et al. Review of the clinical pharmacokinetics of artesunate and its active metabolite, dyhydroartemisinin, following intraveneous, intramuscular, oral or rectal administration. Malar. J. 10, 263 (2011).

26 Tanaka, C. et al. Clinical pharmacokinetics of BCR-ABL tyrosine kinase inhibitor nilotinib. Clin. Pharmacol. Ther. 87, 197-203 (2010).
27 Faiver, S. et al. Molecular basis for sunitinib efficacy and future clinical development. Nat. Rev. Drug Discov. 6, 734-745 (2007).

28 Wilhelm, S. M. et al. Preclinical overview of sorafenib, a multikinase inhibitor that targets both Raf and VEGF and PDGF receptor tyrosine kinase signaling. Mol. Cancer Ther. 7, 3129-3140 (2008).

29 Bonomi, P. Erlotinib: a new therapeutic approach for non-small cell lung cancer. Expert Opin. Investig. Drugs 12, 1395-401 (2003).

30 Medina, P. J. \& Goodin, S. Lapatinib: a dual inhibitor of human epidermal growth factor receptor tyrosine kinases. Clin. Ther. 30, 1426-1447 (2008).

31 Wei G. et al. First-line treatment for chronic myeloid leukemia: dasatinib, nilotinib, or imatinib. J. Hematol. Oncol. 3, 47 (2010). 